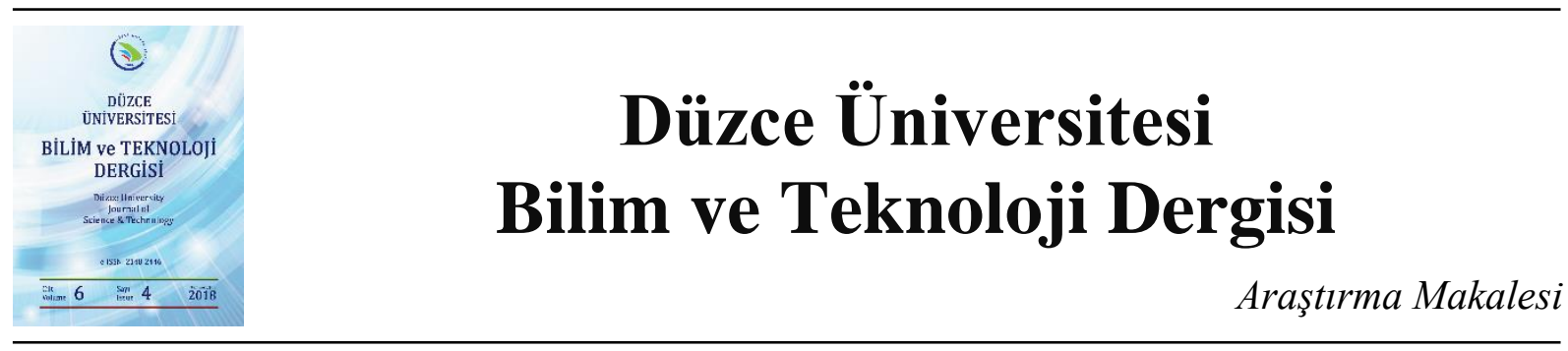

\section{Klima Santrallerinde Yoğuşan Suyun Geri Kazanımı İçin Alternatif Yöntemler}

\author{
Ali Etem GÜREL ${ }^{\mathrm{a}^{*}}$, İlhan CEYLAN ${ }^{\mathrm{b}}$, Alper ERGÜN ${ }^{\mathrm{b}}$, Bahadır ACAR ${ }^{\mathrm{b}}$ \\ ${ }^{a}$ Makine ve Imalat Mühendisliği Bölümü, Teknoloji Fakültesi, Düzce Üniversitesi, Düzce, TÜRKIYYE \\ ${ }^{b}$ Enerji Sistemleri Mühendisliği Bölümü, Teknoloji Fakültesi, Karabük Üniversitesi, Karabük, TÜRKIYE \\ * Sorumlu yazarın e-posta adresi: etemgurel@gmail.com
}

\begin{abstract}
ÖZET
Merkezi 1sıtma ve soğutma sistemlerinin en önemli parçası olan klima santrallerinde soğutucu serpantin üzerinden büyük miktarda su yoğuşmakta ve bu su genellikle en yakın gidere verilmektedir. Uygulamada da bu su, büyük bir atık olarak nitelendirilmektedir. Hâlbuki özellikle \%100 dış hava ile çalışan sistemlerdeki bu soğuk su depolanarak evaporatif soğutma da dâhil olmak üzere birçok uygulamada değerlendirilebilir. Bu çalışmada, klima santrallerinde yoğuşan suyun yeniden kullanımına yönelik farklı tasarımlar önerilmiştir. Çalışmada üç farklı sistem üzerinde incelemeler gerçekleştirilmiştir. Birinci sistemde $\% 100$ taze havalı bir klima santralinden elde edilen yoğuşma suyunun, karışım havalı bir klima santralinin serpantininde ön soğutucu olarak kullanılması incelenmiştir. İkinci sistemde ise \%100 taze havalı veya karışım havalı klima santralinin soğutucu serpantininde yoğuşan suyun, bir soğutma kuleli chiller cihazında besleme suyu olarak değerlendirilmesi araştırılmış̧ır. Üçüncü sistemde ise \%100 taze havalı veya karışım havalı klima santralinin soğutucu serpantininde yoğuşan suyun, hava soğutmalı kondenserli bir chiller cihazında kullanımı incelenmiştir. Yapılan psikrometrik hesaplamalar, \%100 taze hava ile çalışan bir klima santralinde yaklaşık 80 kW'lık gizli 1sının, tasarlanan bu sistemler aracıllğıyla duyulur 1sı olarak kullanılabileceğini göstermiştir.
\end{abstract}

Anahtar Kelimeler: Klima santralleri, Isı geri kazanımı, Enerji tasarrufu.

\section{The Alternative Methods for Recovery of Condensed Water in Air Handling Systems}

\begin{abstract}
$\underline{\text { ABSTRACT }}$
The most important parts of central heating and cooling systems are air handling units. In the air handling units, large amounts of water condense from the cooling coil and this water is usually given to the waste water line. In practice this water is described as a major waste. Whereas, this cold water in systems operating with $100 \%$ outside air can be stored and it can be evaluated in many applications including evaporative cooling. In this study, different designs were proposed for the recovery of condensed water in air handling units. Studies have been carried out on three different systems. In the first system, the using of the condensed water obtained from
\end{abstract}


the $100 \%$ fresh air handling units as a precooler in a coil of an air-handling unit with a mixture air was investigated. In the second system, the condensing water in the cooling coil of the $100 \%$ fresh air or mixed air handling unit was investigated as feeding water in a chiller device with cooling tower. In the third system, the using of the water, which was condensed in the $100 \%$ fresh-air or mixed air handling units, in the chiller device with air cooled condenser was examined. Psychrometric calculations show that a latent heat of about $80 \mathrm{~kW}$ in an air conditioning unit operating with $100 \%$ fresh air can be used as sensible heat through these designed systems.

Keywords: Air handling systems, Heat recovery, Energy saving.

\section{GIRISS}

$\mathrm{D}$ ünya genelindeki hızlı nüfus artışı, teknolojik gelişmeler vb. etkenler enerji tüketimini özellikle son yıllarda büyük bir hızla artırmıştır. Bu hızlı artış, enerji kaynaklarının tükenmesi, küresel ısınma, sera etkisi, ülkeler arası gerilimler gibi pek çok problemi de beraberinde getirmiştir.

Dünya ölçeğinde kentsel yaşamının artışı ile birlikte, binalarda gerçekleşen enerji tüketimi de büyük bir artış göstermiştir. Toplumun refah seviyesine bağlı olarak ihtiyaçların miktar ve çeşitliliğinin artması ile binalarda kullanılan enerji miktarı da yıldan yıla artış göstermektedir. Küresel enerji tüketiminin yaklaşı \%40'ının binalarda gerçekleşmesinden dolayı, atmosfere salınan $\mathrm{CO}_{2}$ 'nin \%30'undan fazlasından sorumlu olarak binalar gösterilmektedir [1-3].

Türkiye ölçeğinde enerji tüketimleri sektörel olarak ele alındığında, hizmet sektörü ile ulaştırma sektörü yılık bazda sırasıyla \%6.2 ve \%5.1 oranında artış göstererek enerji tüketimlerinin en hızlı arttığı iki sektör olmuştur. Bu iki sektörü, sanayi sektörü \%2.4 ve konut sektörü de $\% 2$ 'lik artış oranı ile takip etmektedir. Tarım sektörünün enerji tüketiminde ise yıllık bazda ortalama \%1.7’lik bir artış görülmüştür [4].

Verilen bu rakamlar konut sektöründeki enerji tüketimine dikkat çekmesi açısından oldukça önemlidir. Isıtma ve soğutma sistemlerinin binaların toplam enerji tüketiminin yaklaşık yarısını oluşturduğu bilinen bir gerçektir $[5,6]$. Bu değerler incelendiğinde, konut sektöründe enerji tasarrufuna dair gerçekleştirilecek olan çalışmaların önemi daha iyi bir şekilde kavranabilir.

Enerjinin kullanıldığ 1 her alanda olduğu gibi, iklimlendirme sistemlerinde enerji tüketiminin azaltılması da Türkiye gibi enerjide dışa bağlı ülkeler için oldukça önemlidir. Bu sistemlerin iyileştirilmesi ve verimlerinin artırılmasına yönelik literatürde oldukça farklı çalışmalar gerçekleştirilmiştir.

Dhamneya vd. yaptıkları çalışmada, pencere tipi bir klima sisteminde evaporatif soğutma entegresi ile daha iyi bir 1sıl konfor ve enerji tasarrufu hedeflemişlerdir. Bu sistem ile \%5.18-\%7.39 arasında enerji tasarrufu sağlanabileceğini bildirmişlerdir [7]. Jadhav ve Lele yaptıkları çalışmada, Hindistan iklim şartlarında 1S1 borulu 1S1 değiştiricili bir klima sisteminde teorik enerji tasarrufu potansiyelini incelemişlerdir [8]. Beypazarlı vd. yaptıkları çalışmada, klasik sistemlere alternatif olarak uyguladıkları sistemde taze hava ve resirkülasyon havası kullanmışlardır. Örnek bir proje üzerinde her 
iki sistem için yapılan hesaplamalarda, klasik sistemde 1sıtmada $5980 \mathrm{kWh} /$ gün, soğutmada 9080 $\mathrm{kWh} /$ gün enerji tüketimi değerleri elde edilirken, uygulanan yeni yöntem ile 1 sitmada $3670 \mathrm{kWh} /$ gün ve soğutmada $6522 \mathrm{kWh} /$ gün enerji tüketimi hesaplanmıştır [9]. Sögüt ve Karakoç çalışmalarında, klimalarda enerji verimliliğinde farklı bir yaklaşım olarak ekserjetik verimlilik oranı ve çevresel etki oranı parametrelerine bağlı bir enerji etiketlemesi gerçekleştirmişlerdir. Yapılan analizlerde benzer soğutma kapasitesine sahip klimaların tanımlanan değerlerden farklı özellik gösterdiği görülmüştür [10]. Ceylan vd. yaptıkları çalışmada, toprak kaynaklı bir evaporatif soğutma sistemini termodinamik ve psikrometrik açıdan incelemişlerdir. Yaptıkları deney düzeneğinde evaporatif soğutma ile yüksek bağıl nem değerine ulaşılan ortamlarda konfor şartlarının sağlanması amaçlanmıştır. Çalışma sonucunda elde edilen değerlerde serinletme etkinliğini ortalama \%38 ve ortalama bağll nemi ise \%54 olarak tespit etmişlerdir [11]. Jaber ve Ezzat, egzoz havalı evaporatif soğutma sistemi ile entegre bir enerji geri kazanımı modelinin termal performansını, Akdeniz ikliminde teorik ve deneysel olarak test etmişlerdir. Çalışmada giriş sıcaklığının, $24.4{ }^{\circ} \mathrm{C}$ 'lik ortam sıcaklığında $2.2{ }^{\circ} \mathrm{C}$ ve $35.7{ }^{\circ} \mathrm{C}$ 'lik en yüksek ortam sıcaklığında $7.5^{\circ} \mathrm{C}$ azaldığını tespit etmişlerdir. Böylece soğutma yükünün $\% 13.38$ 'e kadar azaltılabileceğini belirterek, oluşturulan sistemin geri ödeme süresinin 8 yıl olduğunu tespit etmişlerdir [12]. Huang vd. endirekt evaporatif soğutma teknolojisi ile kombine edilmiş sadece hassas 1S1 değiştiricisi kullanan bir 1sı geri kazanım cihazını yatay ve dikey olarak yerleştirerek deneysel analizini yapmışlardır. Farklı yaz koşullarında yaptıkları deneylerde, hem dikey hem de yatay konumda kullanılan endirekt evaporatif soğutmalı sistemin enerji tüketimini azaltabileceğini belirtmişlerdir [13]. Bununla beraber yaptıkları başka bir çalışmada, dikey olarak yerleştirilen sistemin yatay olarak yerleştirilen sisteme göre \%24-44 arasında daha fazla soğutma kapasitesinin olduğunu belirtmişlerdir [14]. Eades, klima santrallerinden yoğuşan suyun hem içme suyu hem de enerji geri kazanım potansiyelini araştırmıştır. Klima santrallerinde yoğuşan suyun ön soğutma ve nem alma işlemleri için ideal bir kaynak olduğunu belirterek, Miami için yaptığı durum çalışmasında içme suyu olarak kullanılması durumunda \%45, enerji geri kazanımı için ise \%13.5 kadar geri kazanım potansiyeli olduğunu tespit etmiştir [15].

Literatür incelendiğinde, enerji verimliliğine yönelik geliştirilen çalışmaların genel olarak bireysel sistemlerde gerçekleştirilen çalışmalar olduğu görülmektedir. Bunun yanında, iklimlendirme sistemlerinde ayar sıcaklığını (set point) değiştirmek suretiyle enerji tasarrufu gerçekleştirilmesine yönelik çalışmalar da bulunmaktadır.

$\mathrm{Bu}$ çalışmada, literatürden farklı olarak, özellikle ticari iklimlendirme sistemlerde yoğuşan suyun geri kazanılması ve bunun farklı tasarımlarla yeniden değerlendirilmesine yönelik üç farklı sistem tasarımı sunulmuştur. Yapılan çalışmanın en büyük farkı, soğutma kulesi ve chiller sistemiyle entegre geri kazanım yöntemlerinin incelenmiş olmasıdır.

\section{SİSTEM TASARIMLARI}

$\mathrm{Bu}$ çalışmada, klima santrallerinde yoğuşan suyun yeniden kazanımı için üç farklı sistem tasarımı önerilmiştir. Bu bölümde tasarlanan sistemler açıklanacaktır.

İlk olarak \%100 taze havalı bir klima santralinden elde edilen yoğuşma suyunun, karışım havalı bir klima santralinin serpantininde ön soğutucu olarak kullanılması ele alınacaktır.

Şekil 1'de bu sistemin detaylı çizimi görülmektedir. 


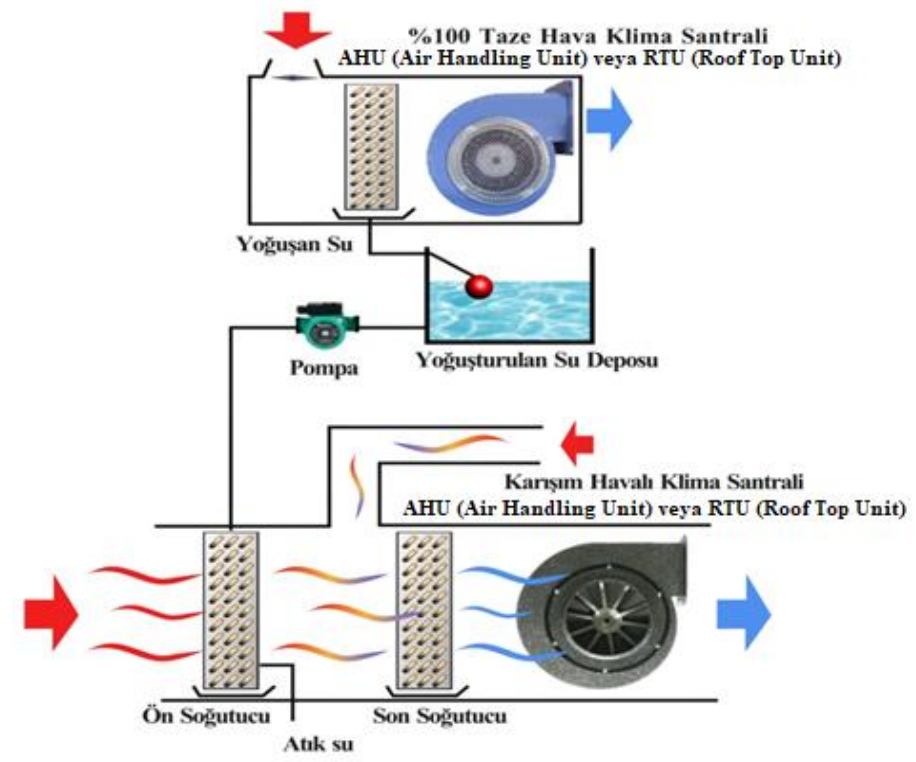

Şekil 1. \%100 taze havalı bir klima santralindeki yoğuşma suyunun karışım havalı klima santralinde değerlendirilmesi

Şekil 1'deki sistemde serpantinde yoğuşan su öncelikle yalıtımlı bir depoda toplanmaktadır. Ardından bu su, pompa aracılığıyla klima santralinde bulunan ve ön soğutucu olarak kullanılan serpantine ön soğutma amacı ile gönderilmektedir. Mahallin soğutma yükünün büyük bir kısmını karşılayabilecek olan sistem, ön soğutucu veya soğutma yükü yeterli olduğu sürece esas soğutucu olarak kullanılabilecektir.

Tasarlanan ikinci sistemde ise \%100 taze havalı veya karışım havalı klima santralinin soğutucu serpantininde yoğuşan su, bir soğutma kuleli chiller cihazında besleme suyu olarak değerlendirilmiştir.

Bu sisteme ait tasarım Şekil 2'de görülmektedir.

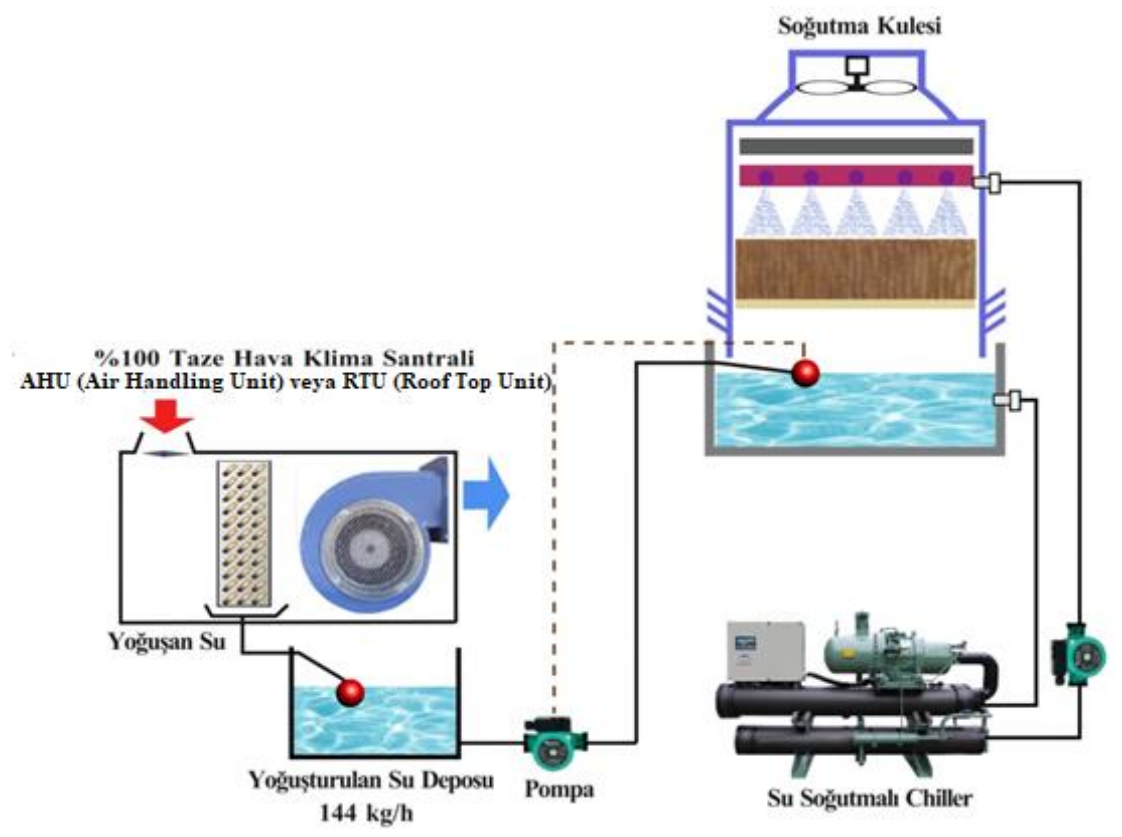

Şekil 2.\%100 taze havalı veya karışım havalı klima santralindeki yoğuşma suyunun soğutma kulesinde değerlendirilmesi 
Tasarlanan bu sistemde de yoğuşturulan su bir depoda toplanacaktır. Fakat bu sistemde su, soğutma kulesinin beslemesi olarak kullanılacaktır. Sistemde zaten soğuk olan su, soğutma kuleli chillerin soğutma yükünü azaltıp enerji tasarrufu sağlayacaktır.

Su soğutmalı chiller cihazının $26-32{ }^{\circ} \mathrm{C}$ sıcaklıklarındaki soğutma kulesine gidiş-dönüş hattındaki su, chiller cihazının kondenserinin ısısının soğutma kulesi ile çevre havasına atılmasını sağlamaktadır. Soğutma kulesinde fan yardımıyla çevre havasıyla temasa geçen su zamanla azalmaktadır. Azalan suyun klima santrallerinde yoğuşan su ile temin edilmesi, soğutma kulesinden dönen suyun sıcaklığını düşürecektir. Bu şekilde chiller cihazının kondenserinden atılan 1sı ve bununla birlikte evaporatörde çekilen 1sı miktarlarında artış olacaktır.

Soğutma cihazının kondenserinin su soğutmalı yerine hava soğutmalı olması durumunda Şekil 3'te önerilen sistem tasarımı ile 1sı geri kazanımı sağlanabilecektir. \%100 taze havalı ya da karışım havalı klima santralinin soğutucu serpantininde yoğuşturulan su, hava soğutmalı kondenserli sistemin serpantini üzerinde evaporatif soğutma işlemine tabi tutulacaktır. Yüksek basınçlı pompa ile yoğuşma deposundan alınan su, nozullar aracılı̆ğ ile kondenser üzerine pülverize edilecektir. Islak kondenser üzerinden atılan 1s1 ve evaporatörden çekilen 1sı artacaktır. Bununla birlikte, sistemin kompresör işi ve elektrik tüketimi düşecektir. Bu değerlerin düşmesi ile birlikte sistemin COP değeri artacaktır.

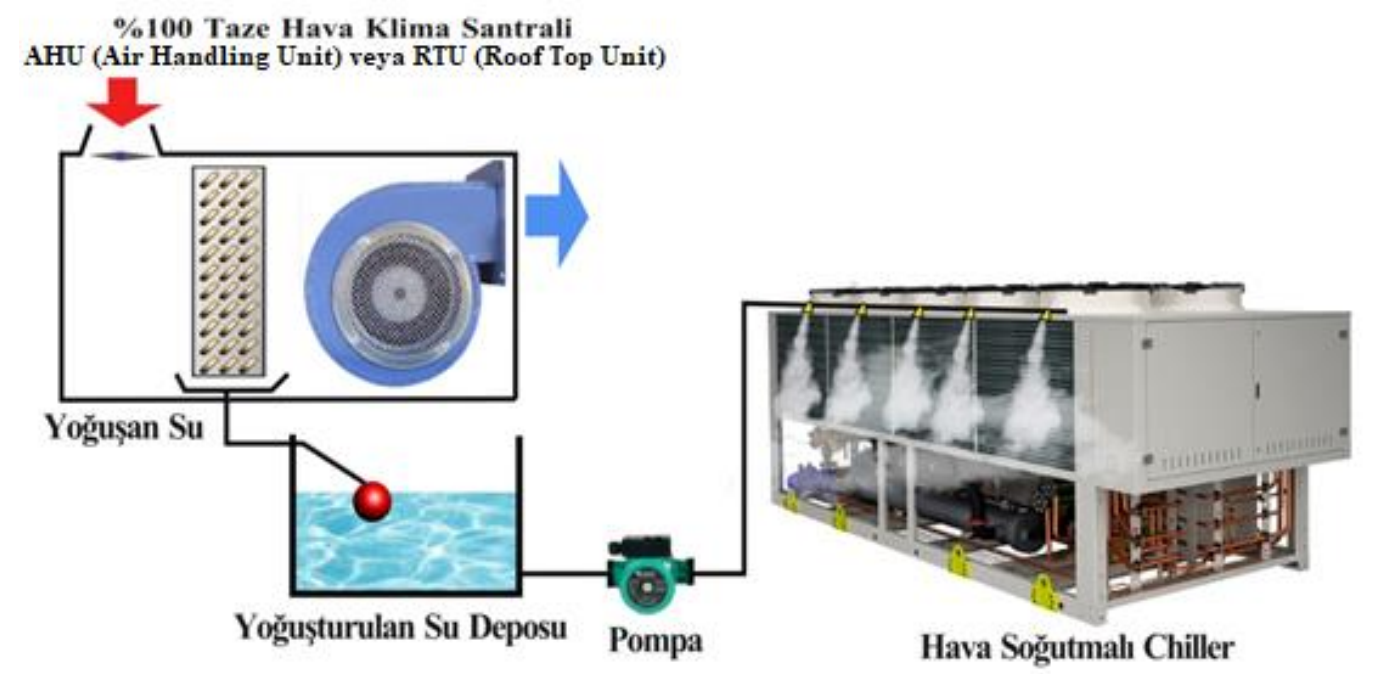

Şekil 3. \%100 taze havalı veya karışım havalı klima santralinden atılan yoğuşma suyunun hava soğutmalı bir chiller cihazında değerlendirilmesi

\section{PSIKROMETRIK ANALIZ}

Yoğuşma suyunun değerlendirilmesine yönelik tasarlanan sistemlerde kullanılabilirliğin tespiti son derece önemlidir. Her ne kadar tasarlanan bu sistemler yüksek maliyetli olmasa da ticari ve termodinamik açıdan tasarruf sağlaması gerekmektedir. Gerçekleştirilen bu tasarımlarla ilgili akla gelebilecek ilk soru, yoğuşacak su miktarının yeterli olup olmayacağıdır.

$\mathrm{Bu}$ bölümde yoğuşacak su miktarının tespiti, örnek bir uygulama üzerinden anlatılacak ve psikrometrik bir analiz gerçekleştirilecektir. Sistemden elde edilebilecek 1sı kazanımının, dolayısıyla 
enerji tasarrufunun daha iyi analiz edilebilmesi için hesaplamalar, soğutma yükünün fazla olduğu İzmir ili verileri kullanılarak gerçekleştirilecektir.

İzmir ilinde bulunan 200 kişilik örnek bir hastane projesi üzerinden, böyle bir sistemin klima santralinden yoğuşacak su miktarının tespiti yapılabilir. İzmir iline ait kuru termometre sıcaklığı $35^{\circ} \mathrm{C}$ yaş termometre sıcaklığı ise $22{ }^{\circ} \mathrm{C}$ olarak alınmıştır. Sistemde chiller cihazından çıkıp klima santrali soğutucu bataryasına (serpantinine) giren suyun sıcaklığ $17^{\circ} \mathrm{C}$ olarak kabul edilmiştir. Yaz şartı için mahal havası sıcaklığ $25^{\circ} \mathrm{C}$ olarak proje değerlerinden alınmıştır. Üfleme havası sıcaklığının, mahal sıcaklığından $8-10^{\circ} \mathrm{C}$ daha düşük olması gerektiğinden üfleme havası sıcaklı̆̆ $15^{\circ} \mathrm{C}$ olarak alınmıştır.

Sistem tasarımı için yapılan kabuller Tablo 1'de verilmiştir.

Tablo 1. Gerçekleştirilen çalışma için yapılan kabuller

\begin{tabular}{cc}
\hline Parametre & Yapılan kabul \\
\hline İl & İzmir \\
\hline Kuru termometre sıcaklığ 1 & $35^{\circ} \mathrm{C}$ \\
\hline Yaş termometre sıcaklığ 1 & $22^{\circ} \mathrm{C}$ \\
\hline $\begin{array}{c}\text { Soğutucu serpantin giriş suyu sıcaklığ } 1 \\
\text { (chiller cihazı çıkış sıcaklığ } 1 \text { ) }\end{array}$ & $7{ }^{\circ} \mathrm{C}$ \\
\hline Mahal sıcaklığ1 & $25^{\circ} \mathrm{C}$ \\
\hline Üfleme havasıs sıcaklığ & $15^{\circ} \mathrm{C}$ \\
\hline Soğutma kulesi için giriş ve çıkış su sıcaklıkları & $26-32^{\circ} \mathrm{C}$ \\
\hline Klima santraline giren hava debisi & $10 \mathrm{~kg} / \mathrm{s}$ \\
\hline
\end{tabular}

Hesaplamalarda kullanılacak olan değerler psikrometrik diyagram aracılığıyla tespit edilmiştir. Çalışmanın psikrometrik analizi Şekil 4'te verilmiştir.

Sistemde 1 saatte yoğuşan su miktarı, psikrometrik diyagram aracılığıyla aşağıdaki eşitlik kullanılarak tespit edilmiştir:

$\sum \dot{m}_{\mathrm{c}}=\dot{m} \times \Delta W \times 3.6$

Bu eşitlikte $\dot{m}_{c ̧}$ saatte yoğuşan su miktarı, $\dot{m}$ klima santraline giren havanın kütlesel debisi $(\mathrm{kg} / \mathrm{s}), W$ ise nem miktarıdır $(\mathrm{g} / \mathrm{kg})$.

Klima santraline giren havanın yoğuşma esnasında soğutucu serpantinden üzerinden çektiği 1sı miktarı ise aşağıdaki eşitlik aracılığıyla tespit edilebilir:

$\dot{Q}_{m c ̧}=\dot{m} \times \Delta h=\dot{m} \times\left(h_{2}-h_{1}\right)$

Burada $\dot{Q}_{m c ̧}$ klima santralinin soğutucu serpantininden çekilen gizli 1sı miktarıdır, $\dot{m}$ klima santraline giren havanın kütlesel debisi, $h$ ise giriş ve çıkıştaki entalpi $(\mathrm{kJ} / \mathrm{kg})$ değerleridir. 


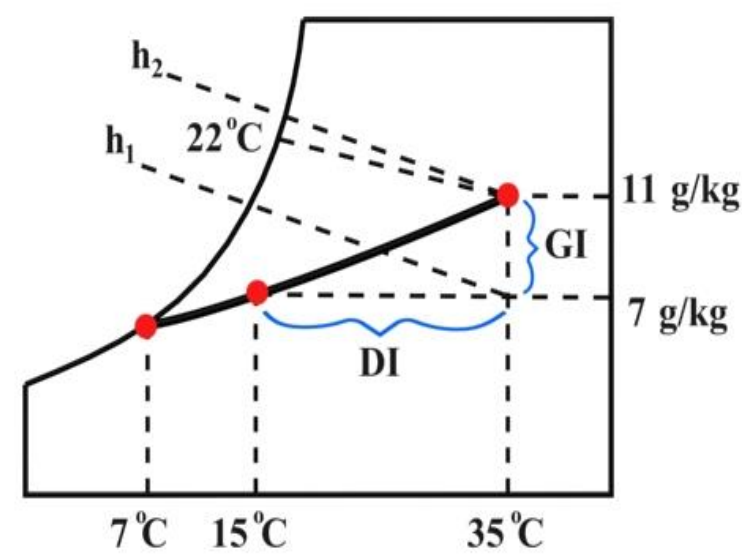

Şekil 4. İzmir ilinin dı̧̧ hava şartlarına göre oluşturulan diyagram

Çalışmada, klima santraline giren hava debisinin $10 \mathrm{~kg} / \mathrm{s}$ olduğu kabul edilmiştir. Psikrometrik diyagram aracılığıyla elde edilen değerler Eşitlik 1'de yerine yerleştirildiğinde,

$\sum \dot{m}_{c ̧}=\dot{m} \times \Delta W \times 3.6=10 \times(11-7)=144 \mathrm{~kg} / \mathrm{h}$ olarak hesaplanır.

Görüldüğü gibi klima santralinin soğutucu serpantininden saatte $144 \mathrm{~kg}$ su yoğuşmaktadır. Bu büyük miktarda atık su anlamına gelmektedir. Yoğuşan su miktarına göre geri kazanılabilecek 1sı miktarını hesaplayabilmek için diyagramdan elde edilen entalpi değerleri Eşitlik 2'de yerine yazılır. Bu durumda gizli ısı miktarı şu şeklide hesaplanır:

$\dot{Q}_{m c}=\dot{m} \times \Delta h=\dot{m} \times\left(h_{2}-h_{1}\right)=10 \times(62-54)=80 \mathrm{~kW}$

Başka bir ifade ile klima santraline giren dış havadan, klima santralinin soğutucu serpantini aracıllı̆ ile $80 \mathrm{~kW}$ 1sı çekilmekte ve serpantin üzerinde yoğuşma gerçekleşmektedir. \%100 taze hava ile çalışan bir klima santralinde yaklaşık 80 kW'lık gizli 1sı, tasarlanan sistemler aracılığıyla duyulur 1sı olarak kullanılabilir.

\section{SONUC VE ÖNERILER}

Yapılan bu çalışmada, oldukça fazla enerji tüketimine sahip klima santrallerinde yoğuşan suyun geri kazanım yöntemleri araştırılmış ve elde edilen sonuçlar maddeler halinde sıralanmıştır:

- $\quad \% 100$ taze havalı santrallerde serpantin üzerinde yoğuşan yüksek miktarda su, genellikle atık olarak nitelendirilmekteyken, tasarlanan sistemler ile $80 \mathrm{~kW}$ 'lık bir gizli isının duyulur is olarak değerlendirilebileceği gösterilmiştir.

- Tasarlanan bu sistemler, mevcut sistemlere oldukça kolay entegre edilebilirler. Bu sayede mevcut sistemler üzerinde büyük değişikliklere gerek duyulmaksızın işletmeye alınabilirler. Tasarımların en önemli özelliklerinden biri budur. 
- Tasarlanan sistemlerin yatırım maliyeti oldukça düşüktür. Sadece tesisat sistemlerinde yapılacak değişiklikler ve ek bir pompa tasarımları devreye almak için yeterli olacaktır.

- Çalışmada elde edilecek tasarruf miktarı, yoğuşabilecek su miktarı ile doğrudan ilişkilidir. Bu nedenle yüksek soğutma yükü bulunan bölgelerde gerçekleştirilecek tasarruf miktarının daha fazla olacağ 1 bilinmelidir.

- Gerçekleştirilen tasarımlar karmaşık kontrol sistemlerine ihtiyaç duymasalar da, verimli çalışabilmeleri için otomasyon sistemleri ile adapte edilip optimum çalışma koşulları sağlanmalıdır.

- Tasarlanan üçüncü sistemde yoğuşma suyu nozullar tarafından kondenser üzerine püskürtülmektedir. Kondenserin yapısı, su tarafından zarar görmeyecek şekilde seçilmelidir.

- Yoğuşan su evaporatif soğutma uygulamalarında da kullanılabilir.

\section{$\underline{\text { V. KAYNAKLAR }}$}

[1] Y. Guo, Z. Tan, H. Chen, G. Li, J. Wang, R. Huang and T. Ahmad, "Deep Learning-Based Fault Diagnosis of Variable Refrigerant Flow Air-Conditioning System for Building Energy Saving," Applied Energy, vol. 225, pp. 732-745, 2018.

[2] T. Hong, C. Koo, J. Kim, M. Lee and K. Jeong, "A Review on Sustainable Construction Management Strategies for Monitoring, Diagnosing, and Retrofitting The Building's Dynamic Energy Performance: Focused on the Operation and Maintenance Phase," Applied Energy, vol. 155, pp. 671707, 2015.

[3] L. Yang, H. Yan and J.C. Lam, "Thermal Comfort and Building Energy Consumption Implications-A Review," Applied Energy, vol. 115, pp. 164-173, 2014.

[4] Enerji Verimliliği Dairesi Başkanlığı Ölçme ve Değerlendirme Grubu, "Türkiye Enerji Verimliliği Geliş̧im Raporu” Yenilenebilir Enerji Genel Müdürlüğü, Türkiye, Rap. 1-2, 2018.

[5] X. Yu, D. Yan, K. Sun, T. Hong and D. Zhu, "Comparative Study of the Cooling Energy Performance of Variable Refrigerant Flow Systems and Variable Air Volume Systems in Office Buildings," Applied Energy, vol. 183, 725-36, 2016.

[6] A. Costa, M.M. Keane, J.I. Torrens and E. Corry, "Building Operation and Energy Performance: Monitoring, Analysis and Optimization Toolkit," Applied Energy, vol. 101, pp. 310316, 2013.

[7] A.K. Dhamneya, S.P.S. Rajput and A. Singh, "Theoretical Performance Analysis of Window Air Conditioner Combined with Evaporative Cooling for Better Indoor Thermal Comfort and Energy Saving," Journal of Building Engineering, vol. 17, pp. 52-64, 2018. 
[8] T.S. Jadhav and M.M. Lele, "Theoretical Energy Saving Analysis of Air Conditioning System Using Heat Pipe Heat Exchanger for Indian Climatic Zones," Engineering Science and Technology, an International Journal, vol. 18, no. 4, pp. 669-673, 2015.

[9] Ş. Beypazarlı, H. Ayar ve M. Aktaş, "İklimlendirme Sistemlerinde Enerji Verimliliği ve Konfor Artışı için Alternatif Bir Yöntemin Analizi," Ileri Teknoloji Bilimleri Dergisi, c. 5, s. 2, ss. $52-65,2016$.

[10] M.Z. Söğüt ve H. Karakoç, "Klimalarda Enerji Verimliliği Sınıflandırılmasında Farklı Bir Yaklaşım: Ekserjetik Verimlilik Oranı ve Çevresel Etki Oranı," Tesisat Mühendisliği Dergisi, c. 135, ss. $50-60,2013$

[11] İ. Ceylan, A. Ergün, B. Acar and M. Aydın, "Psychometric and thermodynamic analysis of new ground source evaporative cooling system," Energy and Buildings, vol. 119, pp. 20-27, 2016.

[12] S. Jaber and W. A. Ezzat. "Investigation of energy recovery with exhaust air evaporative cooling in ventilation system." Energy and Buildings, vol.139, pp. 439-448, 2017.

[13] S. Huang, Y.W. Li, J. Lu and Y.C. Li, "Experimental study on two type of indirect evaporative cooling heat recovery ventilator." Procedia Engineering, vol. 205, pp. 4105-4110, 2017.

[14] W.Y. Li, Y.C. Li, L.Y. Zeng and J. Lu, "Comparative study of vertical and horizontal indirect evaporative cooling heat recovery exchangers". International Journal of Heat and Mass Transfer, vol. 124, pp. 1245-1261 2018.

[15] W.G. Eades, "Energy and water recovery using air-handling unit condensate from laboratory HVAC systems" Sustainable Cities and Society, vol. 42, pp.162-175, 2018. 